Jurnal Widya Laksana, Vol.10, No.2, Agustus 2021

\title{
KONSTRUKSI SOSIAL MELALUI KOMPETISI SEPAKBOLA WANITA
}

\author{
Rumi lqbal Doewes ${ }^{1}$, M. Furqon Hidayatullah ${ }^{2}$, Dede Irawan $^{3}$, \\ Rony Syaifullah ${ }^{4}$, Haris Nugroho ${ }^{5}$ \\ 1,2,4,5 Fakultas Keolahragaan, Universitas Sebelas Maret Surakarta, Indonesia \\ ${ }^{3}$ Student Doktor program Study Ilmu Keolahragaan Universitas Negeri Yogyakarta \\ e-mail king.doewes@staff.uns.ac.id
}

\begin{abstract}
Abstrak
Pemaknaan suatu individu dalam lingkungannya disebut sebagai konstruksi sosial. Sosial atau masyarakat menganggap bahwa sepakbola adalah olahraga yang hanya dapat dimainkan oleh laki-laki. Wanita memiliki hak yang sama untuk bermain sepakbola. Permainan wanita walaupun lebih lambat secara fundamental dan bola dimainkan lebih lama akan tetapi dapat meminimalisir terjadi pelanggaran atau permainan agresif. Tujuan pengabdian ini adalah untuk menkonstruksi sosial bahwa sepakbola dapat dimainkan oleh wanita, wanita dapat berkompetisi dan berprestasi dalam permainan sepakbola. Metode pengabdian dilakukan dengan sosialisasi dan coaching clinic mitra pengabdian yaitu Putri Surakarta; evaluasi dilakukan dengan survey tingkat pelaksanaan kegiatan dan kompetisi sepakbola menggunakan sistem grup dimana grup terdiri dari 3 dan 4 tim. Hasil survey dihasilkan, kualitas materi termasuk dalam kategori baik dengan nilai 3.18, kesesuaian materi dengan kebutuhan peserta termasuk dalam kategori baik dengan nilai 3.15, kualitas narasumber termasuk dalam kategori baik dengan nilai 3.37, dan ketepatan waktu penyelenggaraan termasuk dalam kategori sangat baik dengan nilai 3.40. Kesimpulan pengabdian ini adalah pemain sepakbola wanita mengkonstruksikan sepakbola sebagai olahraga yang dapat dimainkan wanita serta wanita dapat ikut serta dalam kompetisi sepakbola dan menjadi pemenang atau berprestasi sebagai atlet sepakbola wanita.
\end{abstract}

Kata kunci: Konstruksi Sosial; Kompetisi; Sepakbola; Wanita

\begin{abstract}
The meaning of an individual in his environment is called a social construction. Social or society assumes that football is a sport that can only be played by men. Women have equal rights to play football. Although the women's game is fundamentally slower and the ball is played longer, it can minimize violations or aggressive play. The purpose of this devotion is to construct socially that football can be played by women, women can compete and achievement in football games. The devotion method is carried out through socialization and coaching clinic; devotion partners i.e. Putri Surakarta; The evaluation is carried out with survey level of activity implementation and a football competition using a group system where the group consists of 3 and 4 teams. The survey results, the quality of the material was included in the good category with a score of 3.18 , the suitability of the material to the needs of the participants was included in the
\end{abstract}


good category with a score of 3.15 , the quality of the resource persons was included in the good category with a score of 3.37, and the timeliness of the implementation was included in the very good category with a score of 3.40. The conclusion of this devotion is that women's football players construct football as a sport that women can play and women can take part in football competitions and become winners or achievers as women's football athletes.

Keywords : Social Construction; Competition; Football; Woman

\section{PENDAHULUAN}

Konstruksi

sosial atau konstruksionisme sosial adalah teori ilmu sosiologi dan komunikasi yang meneliti perkembangan secara bersama-sama yang dibangun untuk memahami dunia (Gablin, 2014). Konstruksi sosial merupakan proses sosial melalui tindakan dan interaksi individu. Individu menjadi penentu dalam dunia sosial yang dikonstruksi berdasarkan kehendaknya. Pada dasarnya, manusia mempunyai kebebasan bertindak tapi tetap dalam batasan control pranata sosial. Pemaknaan suatu individu dalam lingkungannya disebut sebagai konstruksi sosial. Sosial atau masyarakat menganggap bahwa sepakbola adalah olahraga yang hanya dapat dimainkan oleh laki-laki. Pemain sepakbola dituntut untuk berlari, mengejar bola, dan berebut bola dengan lawan yang dapat terjadi benturan. Olahraga sepakbola telah diakui oleh para bakat untuk menyesuaikan dan berdampak pada konstruksi identitas sosial (Al Ganideh, 2020). Sepakbola adalah salah satu olahraga yang paling sering dimainkan dan ditonton pada saat ini dan satusatunya alat yang digunakan adalah bola sepakbola (Hussain, Shah, \& Shahzad, 2020).

Munculnya atlet dan tim elit wanita (termasuk sepakbola) telah mengubah idealisme femininitas termasuk kemampuan fisik dan daya saing (Midtgaard et al., 2020). Olahraga pada kalangan wanita, perhatian terutama pada ketersediaan energi yang rendah, gangguan menstruasi dan rendahnya kepadatan mineral tulang (Dobrowolski \& Włodarek, 2020). Secara biologis, wanita dan laki-laki memiliki fisik yang berbeda dan merupakan variabel yang berpengaruh pada perilaku. Wanita menunjukkan perbedaan hormonal dan fisiologis dengan laki-laki (Philbois et al., 2021). Salah satu faktor yang paling penting ketika pemain wanita berpotensi terjadi siklus menstruasi yang secara negatif mempengaruhi latihan dan performa. Permainan wanita walaupun lebih lambat secara fundamental dan bola dimainkan lebih lama akan tetapi dapat meminimalisir terjadi pelanggaran atau permainan agresif. Pada tanggal 23/03/1895 menjadi perkembangan awal sepakbola 
wanita dengan adanya pertandingan khusus wanita yang diselenggarakan FIFA di London (CUCUI, 2019). Hal ini menjadi perjalanan awal dimana seorang wanita diperbolehkan menjadi atlet dengan syarat bermain secara halus, menutup bagian tubuh dengan tidak boleh disaksikan kaum lelaki, dan berpakaian seperti wanita. Di Indonesia, sepakbola wanita masih merupakan sesuatu yang asing. Oleh karena itu perlunya dibangun suatu anggapan bahwa sepakbola dapat dimainkan oleh wanita. Hal ini dapat dilakukan melalui kompetisi sepakbola wanita dan coaching clinic. Federasi memegang peranan penting dalam keberhasilan sebuah kesebelasan. Sehingga perlunya dukungan federasi untuk menyelenggarakan kompetisi sepakbola bagi kalangan wanita. Tujuan pengabdian ini adalah untuk menkonstruksi sosial bahwa sepakbola dapat dimainkan oleh wanita, wanita dapat berkompetisi dan berprestasi dalam permainan sepakbola.

\section{METODE}

1. Metode pelaksanaan:

a. Sosialisasi

Kegiatan sosialisasi dilaksanakan pada hari Senin dan Selasa, 19-20 April 2021.

b. Coaching Clinic

Coaching clinic adalah pembinaan singkat dalam bentuk pelatihan yang ditujukan untuk penguasaan pengetahuan dan kecakapan serta penguasaan keterampilan fisik (Csp \& Slavik,
2016). Kegiatan coaching clinic dilaksanakan pada hari Rabu dan Kamis, 21-22 April 2021.

Kegiatan coaching clinic yang dilakukan dalam pengabdian ini adalah berupa pelatihan untuk penguasaan keterampilan teknik passing dan shooting.

c. Kompetisi Sepakbola Wanita

Kompetisi sepakbola wanita dilaksanakan 3 hari yaitu JumatMinggu, 23-25 April 2021.

d. Evaluasi

1) Evaluasi kinerja kegiatan berdasarkan tingkat penilaian pelaksanaan kegiatan

Komponen evaluasi pelaksanaan kegiatan berkaitan dengan kualitas materi, kesesuaian materi, peran narasumber, dan ketepatan waktu penyelenggaraan kegiatan. Peserta sebagai responden memberikan tanggapan terhadap keseluruhan materi yang disampaikan narasumber, cara penyajian materi, hingga kesesuaian materi dengan kebutuhan peserta. Selain itu, ketepatan waktu juga menjadi poin penilaian sebagai upaya menumbuhkembangkan budaya menghargai waktu di lingkungan kegiatan. Selain komponen di atas yang kuantitatif sifatnya, evaluasi secara kualitatif juga dilakukan dengan memberikan ruang bagi peserta memberikan saran dan kritik terhadap penyelenggaraan pengabdian. Panitia perlu mendengar lebih mendalam (depthness) akan aspirasi dan opini peserta yang hanya bisa tertampung dalam bentuk kualitatif, 
yang tersedia dalam kolom saran dan kritik.

Untuk menilai evaluasi ini, survey dilakukan dengan memberikan angket tingkat penilaian pelaksanaan kegiatan diberikan kepada peserta. Pengukuran angket menggunakan skala Likert, hasilnya dikategorikan pada tabel berikut:

Tabel 1. Skala Evaluasi Kinerja Kegiatan

\begin{tabular}{cl}
\hline Skala & \multicolumn{1}{c}{ Kategori } \\
\hline $1-1.7$ & Buruk \\
$1.8-2.5$ & Cukup \\
$2.6-3.3$ & Baik \\
$3.4-4$ & Sangat baik \\
\hline
\end{tabular}

2) Evaluasi hasil kegiatan yang dilakukan dengan adanya kompetisi sepakbola wanita dengan sistem kompetisi dimana dalam 1 grup terdapat 3 tim dan 4 tim. Pada system pertandingan ini, terdapat peraturan yang ditetapkan yaitu:

a) Jika ada pertandingan terpaksa dihentikan karena keadaan darurat (force majeur), maka panitia akan menentukan jadwal penggantinya. Penentuan jadwal pengganti ditetapkan oleh panitia.

b) Jika ada pertandingan terpaksa terhenti kurang dari 10 menit dari waktu normal $2 \times 30$ menit maka pertandingan dianggap selesai dengan skor yang ada.

c) Pergantian pemain maksimal 10

d) 2 kartu kuning akumulasi, larangan $1 \mathrm{x}$ bermain

e) Kartu merah akumulasi, larangan $2 x$ bermain.

\section{HASIL DAN PEMBAHASAN}

\section{Sosialisasi}

Suatu kehidupan yang dijalani setiap hari memiliki makna yang mendalam bagi setiap individu. Ketika wanita melakukan aktivitas yang dilakukan pria, bagi masyarakat hal itu termasuk kegiatan yang menyimpang karena wanita telah dikonstruksikan secara sosial (Muharani, Febriani, \& Saputra, 2021). Konstruksi sosial adalah suatu teori sosiologi yang berpijak pada sosiologi pengetahuan. Teori ini terkandung suatu pemahaman bahwa kenyataan dibangun secara sosial, serta kenyataan dan pengetahuan merupakan istilah kunci untuk memahaminya. Oleh karena itu, konstruksi sosial dalam aplikasinya menekuni apa yang ada di masyarakat dan menjadikan setiap konsep yang ada di masyarakat ditetapkan sebagai hal yang nyata (Manuaba, 2008).

Teori ini juga diterapkan dalam olahraga sepakbola. Masyarakat menganggap bahwa sepakbola adalah olahraga yang hanya dapat dimainkan oleh lakilaki. Hal ini karena sepakbola adalah olahraga dimana pemain dituntut untuk berlari, berebut bola, dapat terjadi benturan dengan pemain lawan, permainan yang memiliki resiko cedera tinggi. Padahal, wanita memiliki hak yang sama untuk bermain sepakbola. Oleh karena itu perlu dibangun suatu anggapan bahwa sepakbola dapat dimainkan oleh wanita. Kegiatan diawali dengan sosialisasi melalui workshop mengenai 
pengenalan sepakbola wanita serta mendefinisikan masalah sepakbola dan cara mendesain latihan sepakbola wanita. Workshop ditujukan pada pelatih tiap klub sepakbola wanita. Sosialisasi adalah proses internalisasi pada kelompok target agar memperoleh informasi (Haski-Leventhal, Pournader, \& Leigh, 2020).

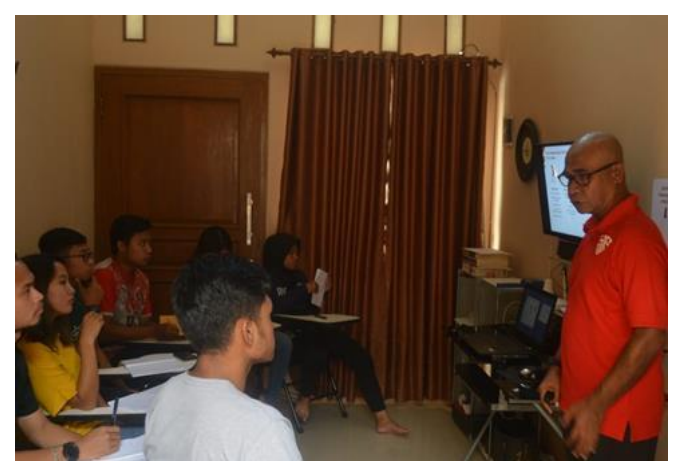

Gambar 1. Foto Kegiatan Workshop yang diikuti Pelatih Setiap Klub Sepakbola Wanita

Materi pengenalan sepakbola wanita dimulai dengan menjelaskan sepakbola wanita adalah olahraga tim yang dimainkan oleh wanita, penjelasan mengenai sejarah kompetisi sepakbola wanita di dunia yang hingga saat ini terdapat sekitar 176 tim pemain sepakbola wanita dari setiap negara mengikuti kompetisi tingkat internasional seperti FIFA Women's World Cup sejak tahun 1991, penjelasan mengenai sepakbola wanita terbaik menurut FIFA yaitu Amerika Serikat, Jerman, Perancis, Belanda, Swedia, Inggris, Australia, Brazil, Kanada, dan Korea Utara. Melalui penjelasan inilah sehingga dapat mengubah anggapan masyarakat khususnya di Indonesia bahwa sepakbola dapat dimainkan oleh wanita dan wanita juga dapat berprestasi melalui berbagai kompetisi sepakbola.

Setelah materi pengenalan sepakbola wanita disampaikan selanjutnya dijelaskan materi kedua yaitu mendefinisikan masalah dan cara mendesain latihan sepakbola wanita. Latihan diperlukan untuk menunjang prestasi wanita dalam kompetisi sepakbola. Melalui latihan, pemain sepakbola wanita dapat meningkatkan keterampilan teknik dan taktik permainan. Pada penyampaian materi, sebelum memulai latihan perlu analisa permasalahan yang muncul dan tujuan latihan dilakukan. Latihan dimulai dengan tahap plan, prepare, conduct, dan evaluate. Pada plan perlu mengenali skill yang akan dilatih. Pada prepare perlu mempersiapkan dan mengkomunikasikan pada pemain, mengambil keputusan, dan eksekusi akan adanya latihan. Pada conduct dilakukan aplikasi dalam permainan kecil dengan penyederhanaan (jumlah pemain sedkit dan area yang kecil). Pada pengaplikasian permainan kecil, perlu dibuat aturan yang tidak keluar dari konteks permainan sepakbola agar skill yang dilatih terangsang dengan baik. Pada evaluate dilakukan aplikasi dalam permainan yang sebenarnya dimana pelatih dapat melihat tingkat kesuksesan latihan yang diberikan. 


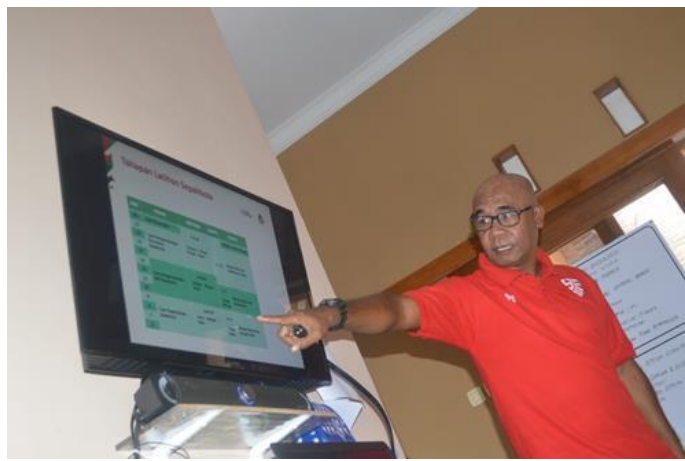

Gambar 2. Foto Narasumber

Menyampaikan Materi Kedua

\section{Coacing Clinic}

Coaching clinic adalah pembinaan singkat dalam bentuk pelatihan yang ditujukan untuk penguasaan pengetahuan dan kecakapan serta penguasaan keterampilan fisik. Setelah dilakukan sosialisasi, dilanjutnya dengan coaching clinic. Coaching clinic pada pengabdian ini berfokus pada penguasaan keterampilan teknik passing dan shooting sepakbola. Pass dapat diartikan sebagai tindakan mengarahkan bola ke salah satu rekan timnya, untuk menempatkan bola dalam kondisi yang menguntungkan terhadap lawannya (Izzo, et al., 2020). Passing merupakan teknik menendang bola yang bertujuan untuk mengoperkan bola kepada teman sendiri dalam permainan sepakbola. Passing sering juga disebut umpan. Passing merupakan bagian dari elemen teknik dengan bola dan merupakan salah satu dari teknik belajar yang pertama pada sepakola (Sokoli, et al., 2020). Sedangkan shooting adalah tendangan ke arah gawang untuk menciptakan gol (Gioldasis, 2018).
Shooting mempunyai ciri khas laju bola yang sangat keras dan cepat dan harus memadukan antara kekuatan dan akurasi tembakan. Melalui passing dan shooting yang baik, akan dapat berlari ke ruang yang terbuka dan mengendalikan permainan saat membangun strategi penyerangan. Penguasaan keterampilan teknik passing dan shooting sepakbola sangat dibutuhkan saat dalam pertandingan. Hal ini karena kemampuan passing dan shooting saling melengkapi satu sama lainnya dimana setiap bola yang dioper harus diterima dan dikontrol oleh rekan seregu untuk menciptakan gol dan memenangkan pertandingan atau permainan.

Pada pengabdian ini, coaching clinic penguasaan keterampilan teknik passing dilakukan dengan latihan $4 \mathrm{v} 2+1$, $4 \mathrm{v} 2+3 \mathrm{v} 2$, dan game 6v6. Inti dari latihan ini adalah sebagai media bagi pemain untuk mempelajari komunikasi dan taktik permainan saat kondisi pertandingan menghadapi tekanan lawan. Latihan dilakukan dengan konsep replikasi yang sama dengan pertandingan sebelumnya. Konsep replikasi ini dilakukan dengan prinsip penyederhanaan yang artinya menyederhanakan durasi, intensitas, dan struktur pertandingan yang sesungguhnya. 
Jurnal Widya Laksana, Vol.10, No.2, Agustus 2021

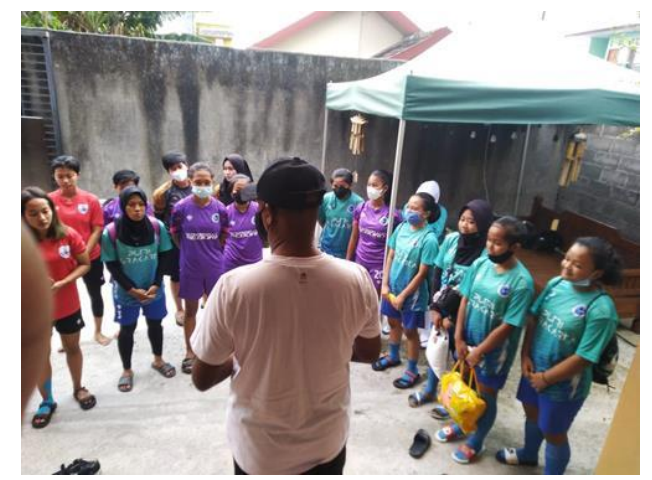

Gambar 3. Foto Pengarahan

Sebelum Dilakukan Coaching Clinic

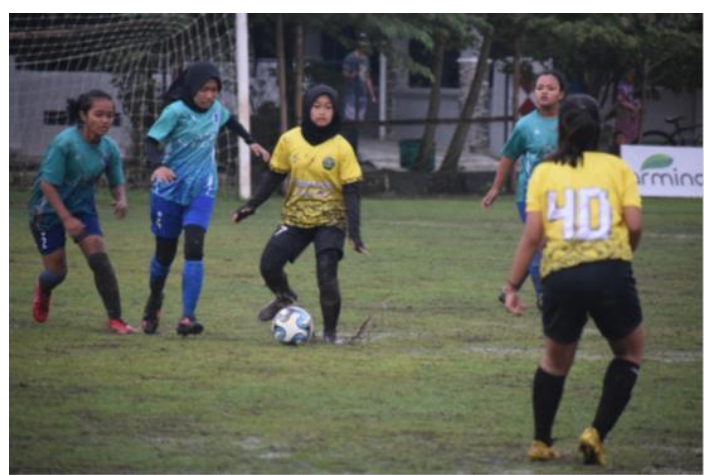

Gambar 4. Foto Coaching Clinic

\section{Evaluasi}

1) Evaluasi Kinerja Kegiatan

Survey dilakukan dengan memberikan angket tingkat penilaian pelaksanaan kegiatan yang meliputi materi relevan dengan isu actual, materi yang disampaikan dapat meningkatkan keterampilan, materi meningkatkan kemampuan untuk bekerja dalam tim, narasumber mampu memberikan informasi yang jelas untuk mencapai hasil terbaik, narasumber mampu memberikan jawaban yang jelas terhadap peserta, waktu penyelenggaraan kegiatan mencukupi kebutuhan, penyelenggaraan kegiatan dilaksanakan tepat waktu sesuai jadwal yang dibagikan ke peserta.

Hasil survey, kualitas materi termasuk dalam kategori baik dengan nilai 3.18, kesesuaian materi dengan kebutuhan peserta termasuk dalam kategori baik dengan nilai 3.15, kualitas narasumber termasuk dalam kategori baik dengan nilai 3.37, dan ketepatan waktu penyelenggaraan termasuk dalam kategori sangat baik dengan nilai 3.40 .

Dalam survey, peserta diberikan pertanyaan terbuka untuk menjaring kritik dan saran. Menurut peserta pengabdian, konstruksi sepakbola ini dapat dilaksanakan di kota-kota yang lain agar persepsi tentang sepakbola itu tidak hanya dilakukan oleh kaum laki-laki tapi juga dapat dilakukan oleh kaum wanita.

2) Evaluasi Hasil Kegiatan

Konstruksi sosial terjadi berdasarkan konsep eksternalisasi, objektivasi, dan internalisasi. Berdasarkan konsep eksternalisasi, seorang wanita menyesuaikan diri 
sebagai atlet sepakbola di kalangan masyarakat. Berdasarkan konsep objektivasi, konstruksi sosial terjadi dengan adanya kelembagaan klub sepakbola wanita. Berdasarkan konsep internalisasi, konstruksi sosial terjadi dimana seorang wanita menjadi anggota di klub sepakbola wanita dengan melaksanakan kegiatan dalam bentuk kompetisi sepakbola wanita yang diikuti oleh 7 klub yaitu Kartini Safin Football yang terdiri dari 7 tim yaitu Samarinda Women, PSW Putri Mataram Sleman, Putri Surakarta, PON Jabar, Bina Setra, Arema Putri, dan SPFA Putri. Kompetisi adalah aktivitas mencapai tujuan dengan cara mengalahkan orang lain atau kelompok. Kompetisi sepakbola yang dijalankan dalam pengabdian ini adalah dengan sistem kompetisi dimana setiap peserta memperoleh kesempatan untuk saling bertanding. Kompetisi ini bertujuan untuk mengetahui hasil coaching clinic yang telah diterapkan. Kompetisi dimenangkan oleh PON Jawa Barat dengan 9 poin.

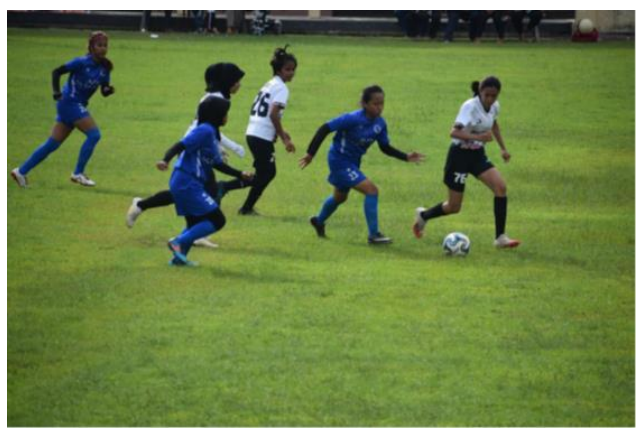

Gambar 5. Foto Kompetisi

\section{KESIMPULAN}

Kesimpulan pengabdian ini adalah pemain sepakbola wanita mengkonstruksikan sepakbola sebagai olahraga yang dapat dimainkan wanita serta wanita dapat ikut serta dalam kompetisi sepakbola dan menjadi pemenang atau berprestasi sebagai atlet sepakbola wanita.

Saran berupa tindakan lanjutan yang perlu dilakukan yaitu terkait pelaksanaan pembinaan jangka panjang pemain sepakbola wanita agar sepakbola wanita Indonesia dapat berkompetisi di Internasional. Hal ini akan menciptakan anggapan bahwa wanita juga dapat berkembang dan berprestasi melalui sepakbola.

\section{DAFTAR PUSTAKA}

Al Ganideh, S. F. (2020). Demystifying Arabs: Is soccer Arab societies' 'crystal ball'? National Identities, $0(0), 1-23$.

Ciesielska, M., \& Jemielniak, D. (2017). Qualitative methodologies in organization studies. Qualitative Methodologies in Organization Studies, 2(December), 1-264. https://doi.org/10.1007/978-3-31965442-3 
Csp, D., \& Slavik, J. (2016). Sports Medicine for Coaches- A Coaching Clinic.

CUCUI, G. G. (2019). Feminin Football in the Physical Education and Sport System. 11th LUMEN International Scientific Conference Communicative Action \& Transdisciplinarity in the Ethical Society, CATES 2018, 23-24 November 2018, Targoviste, Romania, 7(November 2018), 93107.

Dobrowolski, H., \& Włodarek, D. (2020). Low energy availability in group of Polish female soccer players. Roczniki Państwowego Zakładu Higieny, 71(1), 89-96. https://doi.org/10.32394/rpzh.2020 .0106

Galbin, A. (2014). An Introduction to Social Constructionism. Social Research Reports, 26, 82-92

Gioldasis, A. (2018). Changes of Technical Skills during an Official Futsal Game. International Journal of Science Culture and Sport, $6(28)$, 359-371. https://doi.org/10.14486/IntJSCS7 67

Haski-Leventhal, D., Pournader, M., \& Leigh, J.S.A. (2020). Responsible Management Education as Socialization: Business Students' Values, Attitudes and Intentions. Journal of Business Ethics. https://doi.org/10.1007/s10551020-04593-3
Hussain, S. B., Shah, S. I. A., \& Shahzad, A. (2020). Optimization and Aerodynamic Design of a Soccer Ball Using Numerical Analysis. 2020 International Conference on Engineering and Emerging Technologies, ICEET 2020.

https://doi.org/10.1109/ICEET4847 9.2020 .9048220

Izzo R., Rossini U., Raiola G., Palomo A C., \& Varde'i C. H. (2020). Insurgence Of Fatigue And Its Implications In The Selection And Accuracy Of Passes In Football. A Case Study. Journal of Physical Education and Sport, 20(4), 19962002

Manuaba, I.B.P. (2008). Memahami Teori Konstruksi Sosial. Masyarakat, Kebudayaan, dan Politik, XXI(3), 221-230.

Midtgaard, J., Tjørnhøj-Thomsen, T., Rørth, M., Kronborg, M., Bjerre, E., \& Oliffe, J. (2020). Female Partner Experiences of Prostate Cancer Patients' Engagement With A Community-Based Football Intervention: A Qualitative Study. 1-20.

https://doi.org/10.21203/rs.3.rs37615/v1

Muharani, A., Febriani, L., \& Saputra, P.P. (2021). Perempuan Dalam Komunitas Suporter Sepakbola The Babel Mania. Jurnal Sosial dan Sains, 1(2), 93-102.

Philbois, S.V., Facioli, T.P., Gastaldi, A.C., Rodrigues, J.A.L., Tank, J., Fares, T.H., Rodrigues, K.P., \& Souza, H.C.D. (2021). Important 
Jurnal Widya Laksana, Vol.10, No.2, Agustus 2021

Differences

Hypertensive

Women and

Cardiovascular

Control-a Critical

Biology of Sex

12(11).
Between

Middle-Aged

Men in

Autonomic

Appraisal.

Differences,
Sokoli, B., Ibrahimi, G., \& Jahaj, Q. (2020). Differences In Short And Long Passes Of Midfield Footballers. Journal of Education, Health and Sport, 10(2), 140-147. 